\section{MISCELLANEA GEOGRAPHICA}

WARSZAWA 1990

Wiktor Grygorenko

\title{
COGNITIVE AND METHODOLOGICAL ATTRIBUTES OF CARTOGRAPHY
}

Conceptual breakthrough in catography within the last thirty years is manifested by a growing popularity of theoretical orientation whose major aim is to identify the elements and structure of cartography as a discipline of science. An awareness that cartography is poorly developed as far as theory is concerned has embarassed many cartographers and forced them to search desperately for a rapid formulation of a methodological programme. This trend is exemplified by numerous attempts at working out a cognitive model of cartography which would illustrate its strurture and functional mechanism.

The major purpose of cartography, as of any scientific discipline, is its cognitive function. Yet its methodological status is highly peculiar. So far, there has been no agreement among cartographers themselves as regards the proper subject of cartographic research, the true meaning of the term cartographic method, or even the place cartography within a general classification of all sciences! Thus, it is worth trying to explain to what extent the methodological spectrum of cartography, that is, its cognitive and pragmatic functions depend on interdisciplinary influences.

The cognitive function of cartography consists mainly in revealing and explaining the attributes of cartographic methods and mechanisms of research procedures as well as the ways of representing reality on maps. In this sense, the term "methodology of cartography" means a discipline dealing with cartographic methods. Such a definition, however, is inadequate since the methodology of cartography, just like that of any other science, covers not only studies of cartographic methods of presentation and research but also the results of these activities which acquire the form of language structures such as concepts, systems of propositions, definitions and semantic models of maps. In this sense, the methodology of cartography is closely connected with semiotics. Quite frequently, the term "methodology of cartography" also covers 
a set of research directives following the theoretical system of cartography.

Pragmatic function of cartography and, hence, its methodology includes a set of cartographic methods. The term "a set of methods" means a system of rules (norms) for practical application as well as technical means in such activities as: map making, map reproduction, analyses and interpretation of maps, collecting cartographic documentation, education of cartographers and the like.

All these rules and suggestions have envolved in the course of centur:es of cartographers' activities and appear in the form of a number of conventions included in technical instructions, comments on tables of conventional signs and in handbooks of cartography. In this meaning a set of cartographic methods could well serve for many centuries as a substitute for a theory of cartography and contribute toward a comtinuous development of cartography itself.

Cartography is a peculiar example of a discipline the subject of which includes both its research activities and methods as well as the final results of these activities. In this sense, the term cartographic method refers to all of cartographic means of representing reality and changes therein as well as to the means od studying reality on the basis of cartographic products such as, among others, geographical maps. The above definition draws attention to two aspects of cartographic method, namely: A - transmission of information concerning reality with the aid of maps (maps would function here as carriers of information) and $\mathrm{B}$ - the use of maps in the process of studying reality (maps would function here as instruments of research).

A. The cartographic method understood as the carrier of information has at its disposal a whole arsenal of procedures contributing toward the process of: editing, annotating, setting and printing geographical maps.

Among the procedures aimed at carrying information, the most important one refers to a form of cartographic coding and is called cartographic method of presentation.
B. The cartographic method understood as a research activity involves a number of cognitive tools such as analogy, analysis, synthesis, abstraction, generalization and modelling used in the process of studying reality on the basis of maps.

Studying reality by means of maps is called cartographic method of research. 
Cartographic modelling is a highly specific form of cartographic method. The term implies a process of preparing and drafting maps which visually present the spatial structure of actual reality by means of cartographic methods of presentation relevant to all particular elements of that reality. Thus, cartographic modelling refers mainly to a spatial structure of a model, i.e. arrangement of phenomena and, to a a much lesser extent, to inner contents of these phenomena. Naturally, the inner content of phenomena may also provide the subject for modelling, yet, it need not always acquire the form of cartographic model. After all, such graphical details displayed on maps as line-graphs or diagrams (except for band graphs) are practically alien to the idea of cartographic model (Fig. 1)).
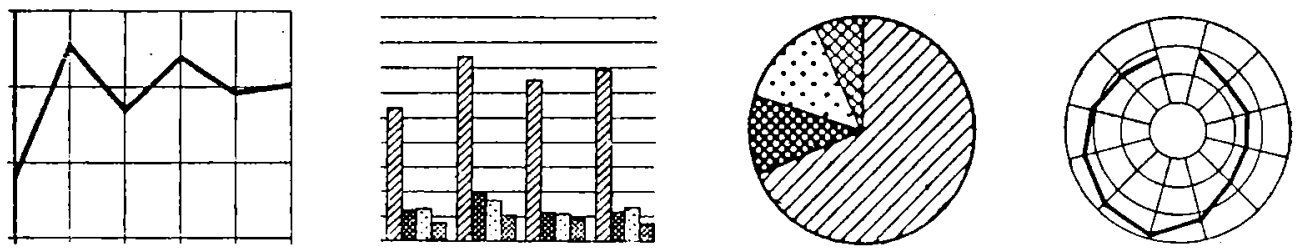

Fig. 1. A variety of symbols placed on the thematic maps.

From the point of view of epistemology, a branch of science is determined by its subject matter. The subject matter of cartography are the regularities of actual reality perceived from the point of view of the peculiarities of space and of concrete objects and phenomena contained in that space; they are all represented on maps by means of a cartographic method of presentation. According to that definition, the subject matter of cartography covers two aspects of cartography as a science: theoretical-methodological and pragmatic.

The theoretical-methodological aspect contributes toward a system of knowledge concerning maps, methods of cartographic studies of concrete reality with the help of maps and also principles of preparing cartographic description of that reality. The pragmatic aspect, on the other hand, covers all kinds of sugestions and directives concerning rational application of cartographic methods in the process of making and using maps.

In view of its specific character, cartography plays, in a sense, an analogous role, to mathematics in relation to other branches of knowledge such as, primarily, natural sciences and humanities, since it studies the ways of representing objects that are identified by other sciences. 
For the benefit of other sciences cartography introduced effective means of representing and studying regularities and characteristic features of natural and social phenomena and all their interrelations within a spatial configuration displayed in graphical form exactly ordered that is reduced to a unified spatial system.

One may consider cartographic forms of expressing three-dimensional space on a two-dimensional plane as a way of representing qualitative and quantitative features of natural and socio-economic phenomena that make up the structure of a given reality. It would further support the analogy between cartography and mathematics, since the discipline aims at developing methods that are used in other sciences for studying with the help of maps of properties of objects and phenomena and their characteristic spatial configuration and to present the results of research by means of cartographic methods.

First of all, this would refer to geography which for many centuries encompassed cartography as a method of describing the location (topography) and the external features of objects on the surface of the Earth. It was closely connected with studies concerning the shape of the Earth and as such, in the 16 th century, cartography came close to geodesy.

It is within the field of geodesy that the scientific premises of cartography, that is the theory of spatial, geometrical transformation of geographical objects and phenomena were formed. At the same time, geodesy aimed at improving methods of topographic measurements and also at introducing new ways of representing topographic objects on maps.

The topographic method of making maps is the best support for a thesis that the space itself within which concrete objects and phenomena take place is a true subject matter of cartography.

Space as a subject for research appears in a number of scientific disciplines. Only cartography, however, takes the arrangement of objects and phenomena in space as a central theme of its interests. Yet as a science, cartography must not be delimited by sets of objects and phenomena only, and hence it cannot be defined solely with respect to the contents but rather with respect to the methods used in description and studying objects and phenomena. Neither should cartography seek a special place in a system of sciences on the basis of a separate category of phenomena but rather it should establish its own identity on its unique point of view and its specific method.

Chorological point of view provides the possibility for explaining the way in which the most diverse observations (data) are linked together by causal relationships and thus endowing various geographic regions with a specific character. The use of its own original research meth- 
ods and scientific description with the help of methods of cartographic presentation provide reasons for considering cartography an independent branch of science. It would not have been possible were cartography to concentrate only on the location of individual objects or on concrete themes of maps.

A capability for generalization consitutes one of the basic premises for the existence of a true science. Cartographic descriptions in the form of maps convey information concerning the configuration of objects and phenomena in space and their characteristic features in the most condensed (abstract) yet, at the same time, sufficiently precise way. Cartographical praxis offers a great variety of such descriptions in the form of maps which have been traditionally divided into two groups: general maps and thematic ones. Actually, this kind of classification is quite irrational since general maps also feature a subject (theme) of some sort. It is - most generally - the topography of the surface of the Earth. The only reason for the distinction of a separate group of thematic maps lies in that they show not only real geographic abjects but also phenomena relating only to the surface of the Earth. For instance, these may be exclusively relations between objects as well as assessments and forecasts relating to concrete events.

The assumption by $M$. Eckert - an authority on theory of cartography, of map's contents as the basic concept in methodological classification of cartography caused a long-term stasis in the field of theory of ethical development of cartography. It was only when the unlimited number of maps' subjects was contrasted with a limited number of cartographic methods as basic theoretical concepts that a real breakthrough occurred on cartography's road to becoming a discipline of science. As a consequence, cartographic terminology was finally precisely defined and a consistent model of cartography's methodological structure was worked out (Fig. 2).

All this has been made possible due to the last fifty years of advancement of cartographic methods. It is precisely cartographic methods of scientific description of objects and phenomena (methods of presentation) on maps and cartographic methods of research that constitute cartography's contribution to the development of methodology of other branches of geography.

Thus, from the point of view of its qualifications as a discipline of science and a generally understood method of designing and the use of maps (that is its purposes) cartography focusses mainly on methods of cartographic presentation and methods of cartographic research. They constitute the first stage of the perfectly symmetrical hierarchical methodological structure of cartography. 
Descending toward lower levels of specification of their aims, cartographic methods of presentation (left branch of the model of methodological structure) became more and more precise. Namely, on the second level, from the point of view of the special character of cartographic definition of actual reality one may distinguish: 1 . methods permitting a detailed specification of the contents as well as of some objects and phenomena of topographic space in analytical approach (corresponding to the scale); 2. methods allowing presentation of ways of distribution and internal characteristics of selected objects and phenomena - synthetical approach. From the point of view of graphic presentation of the contents of the map these two methods of rendering reality result in two types of maps: general and thematic.

On the thind level - types of objects and phenomena as well as ways of their occurrence in concrete reality are taken into consideration as they comstitute the contents of both: general and thematic maps. The character of methods applied on the fourth level depends on data (information) relating to the sort of objects and phenomena. On the lowest - the fifth level one may consider known methods of presentation arranged according to the characteristics which correspond most closely to the character of the data and the sort of objects and phenomena.

Nowadays, the scientific and practical significance of geographic maps is unquestionable to anyone. It has been proved by observation and experience in the sphere of "map-reading ability", practical application of maps for the orientation in the field, solving various scientific and technical problems with the help of a map. Moreover, we find that it requires the knowledge of methodology and technique of taking measurements on maps as well as the knowledge of methodology of analysis and processing of the contents of maps for cognitive purposes. The knowledge and abilities pertaining to these problems constitute the content of cartographic research method, which forms the right branch of the model of methodological structure of cartography.

Methods of cartographic research which involves also various methods of practical use of maps differ among themselves as regards the character of gathering data required for the assessement of connections and relations among objects and phenomena of actual reality. From this point of view, on the second level of application of cartographic research methods one may distinguish cartometric research typical of the use of general maps, and comparative analytical studies related rather to the use of thematic maps.

Research methods used on the third level are classified according to the type of objects and ways of their graphic representation on the 

CLASSIFICATION OF CFITERION

OF CARTOGRAPHIC METHODOLOGICAL

SYSTEM FROM THE POINT OF VIEW:

1. TASKS OF CARTOGRAPHY

II. WAY OF SPACE DEFINITION

III. SORT OF DETAILS AND KIND OF GEOGRAPHICAL PHENOMENA

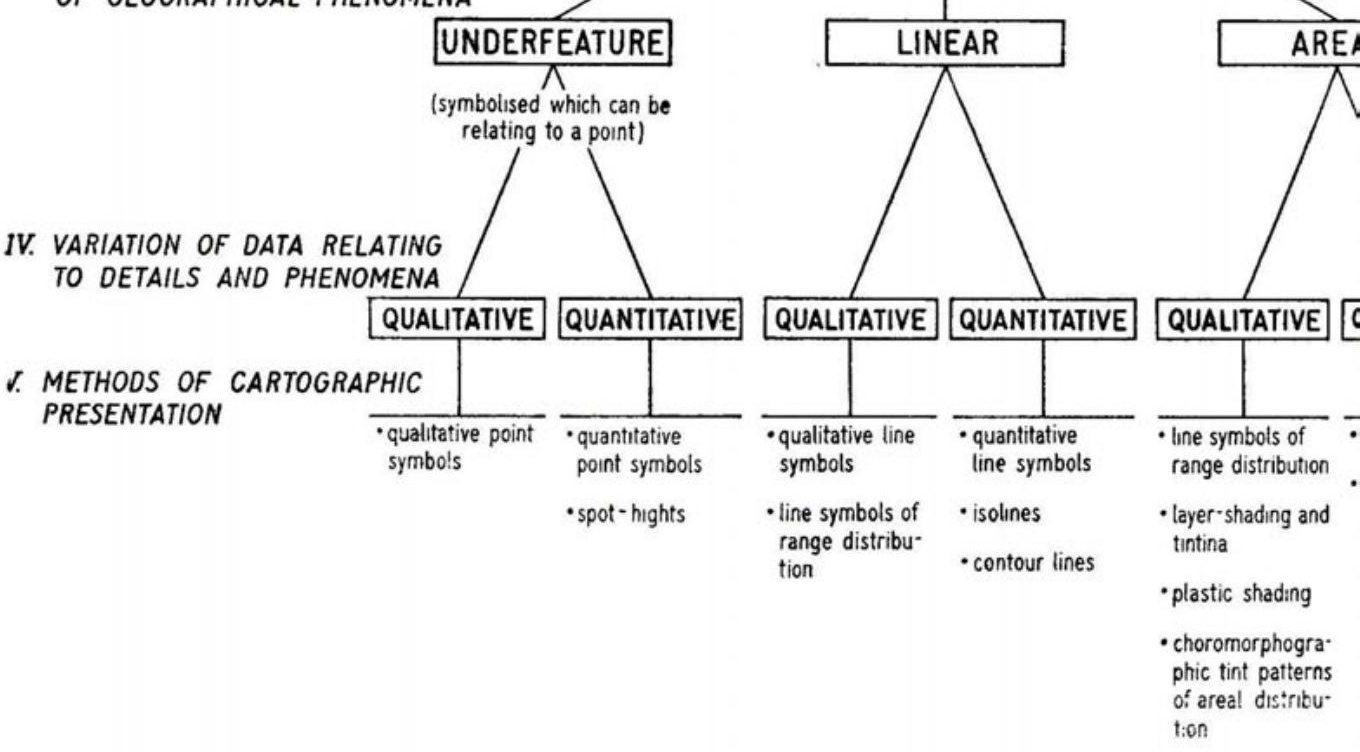




\section{CARTOGRARHY AS}

\section{RESENTATION}

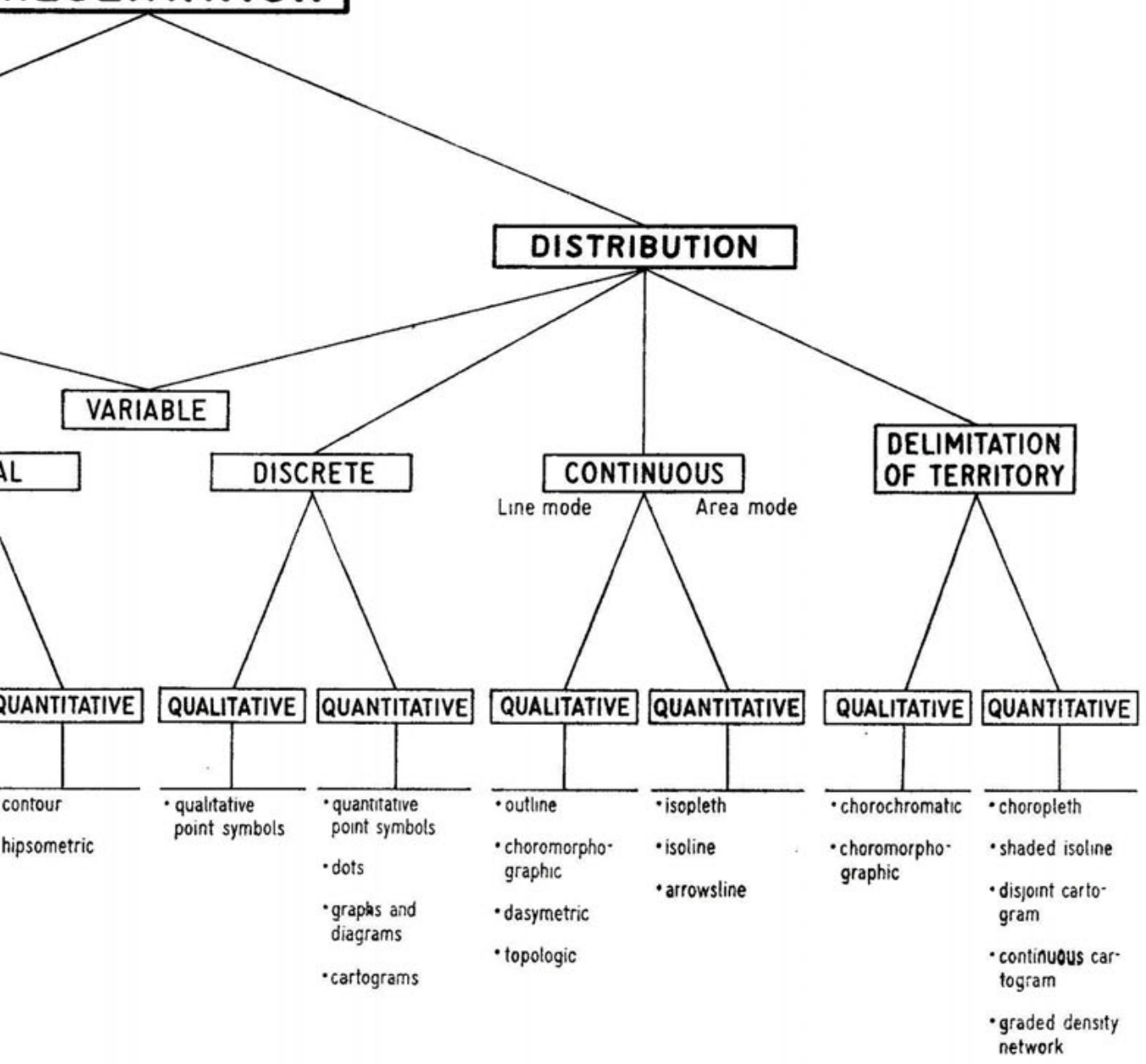




\section{\$ THE METHOD OF}

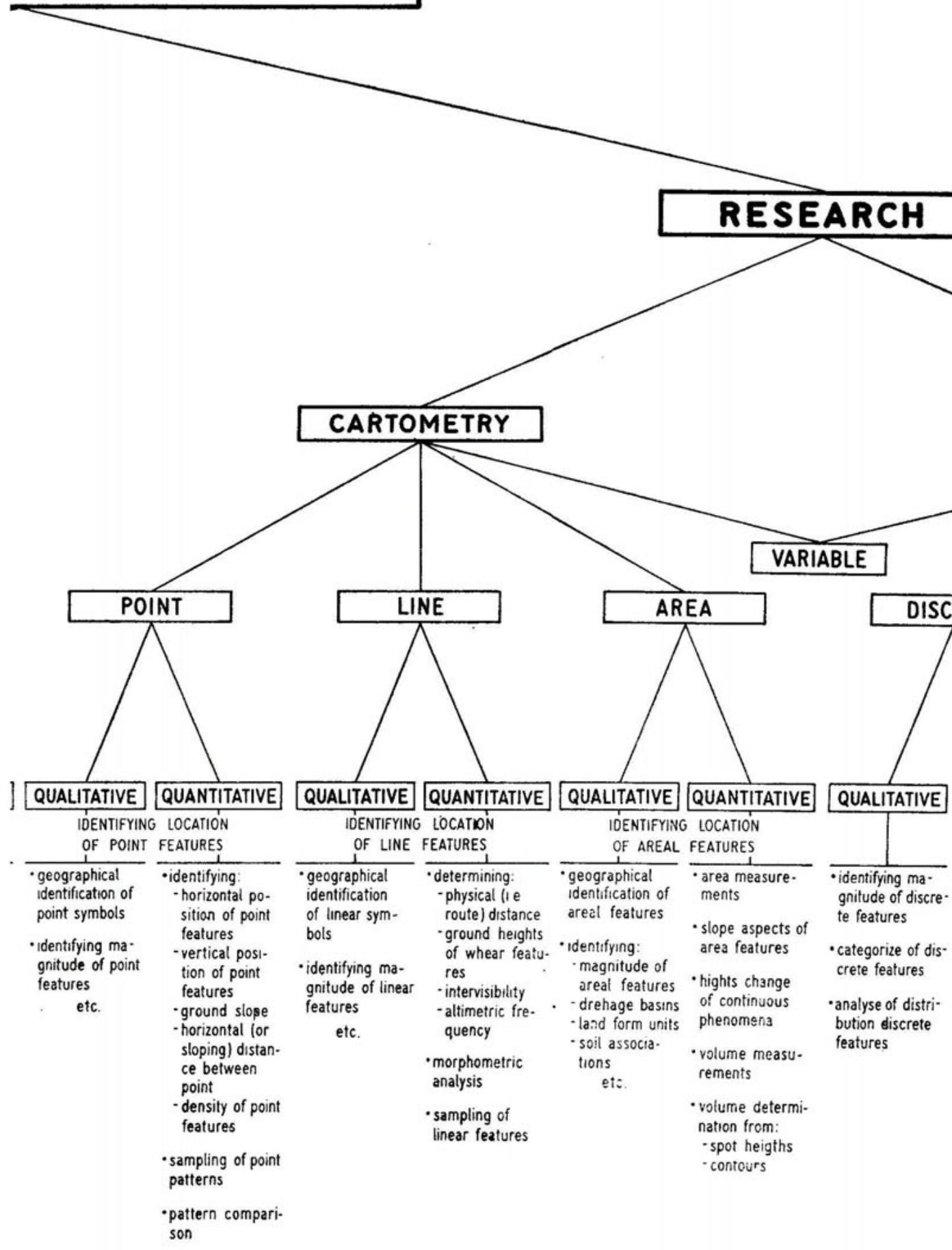


III. KIND OF GEOMETRICAL PHENOMENA AND WAYS OF THEIR GRAPHIC PRESENTATION

RETE

\section{CONTINUOUS} Line mode \ Area mode one and two dimensional

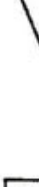
QUANTITATIVE $\mid$
- determining - functional li.e. thematic) distance of the discrete features

- value for space dimension) of the variable discrete feature,

- distribution den sity

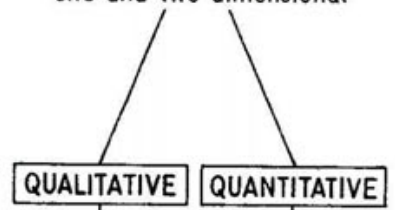

\begin{tabular}{l|}
-identification ma. \\
\hline
\end{tabular} gnitude of linear (and some areal) features near (and areal) features

- sweeping state. ment conception concerned about distributicn of culturat data
- categorize of $\mathrm{H}$ -

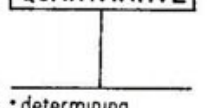

determining.

- distances leither

route or thematic)

- furctional values of whear featu-

res

- Identifying values (as well dimension) of the variable whear symbols by the.

- distrikution fre. quency of iso. prets

- hight of coni.

nuous feciures - profites

$\epsilon \div c$
IV. CHARACTER(ISTIC) OF INFORMATION (DATA) CONCERNED TO RECONNOITED OBJECTS AND PHENOMENA

\section{QUALITATIVE QUANTITATIVE}

\section{RESEARCH METHOOS PROPERTIES}

- identification ma* - determınıng of gnitude of spatial functional value

features of the spatial

- categorize of areal features -identifying values

functional disision well dimension) of the variable areal symbols, by the:

- spatial connec. tivity and hierar. -trend surface chy of discrete analysis continuous and - space dirision erea! features - spatial change tic 

map. While on the fourth level, the choice of research method depends, just as with methods of presentation, on the character of information, that is - whether it concerns qualitative or quantitative features of objects and phenomena presented on the map.

On the last, the fifth, level of the particularization of cartographic research methods, we deal with concrete techniques of studying the contents of the map. They fall into seven divisions:

1. Observation and rational speculation as the basis for conclusions in the form of either verbal description or cartographic representation: choropleths, cartograms, diagrams, correlation isopleths etc.).

2. Cartometric measurements leading to the definition (with the help of general maps) of the following: location of points (objects), length of linear objects, directions, altitude above the sea level, relative altitude, area of surface objects, form volume, slope angle etc.

Thematic maps, on the other-hand, serve to define i.e. number of inhabitants, size and scope of industrial and agricultural production, rate of transportation, volume of traffic etc.

3. Mathematical-graphic analyses, that is the study of graphic structures based on maps such as: profiles, graphs, diagrams, block diagrams, which are forms of image-sign models.

4. Mathematical-statistical analyses which consist in the calculation of statistical indices characteristic of spatial units of the examined area as well as correlation indices relating to spatial and temporal relations among phenomena.

5. Mathematical modelling which consists in that, on the basis of data provided by maps, one can built formulas relating to actual surfaces (i.e. topographical) or abstract (i.e. population density, yearly precipitation, soil fertility in various areas).

6. Map contents processing, which implies activities aiming at secondary (related) maps representing - in a different way - the content of primary map in order to acquire new information as regards geographic phenomena.

7. Stating hypotheses and forecasts relating to spatial relations by means of varied graphic renditions each of which takes into consideration a specific feature of examined phenomenom.

By virtue of the above we can say that particular methods of cartographic research comprise methods based on direct and indirect observation as well as methods of distribution.

Methods of observation relate to the study and topographic knov:ledge of terrains as well as to preparation of general maps. They aim at the supplying of information on the specific contents of the Earth's space. Methods of distribution, on the other hand, relate to various forms 
of economic and administrative activities of state bodies, which require knowledge of not only spation contents of the administered areas but also of the ways of distribution of geographic objects and phenomena in these territories as well as their economic, practical features.

Observation methods include, among others, geodetic and topographic measurements whose aim is to define the location of specific points on the surface of the Earth, to present the shape and size of the Earth. Moreover, they provide ground maps containing quantitative information about objects and phenomena i.e. pedological maps, land use maps and so forth.

Observation methods cover also the method of cartographic compilation. By employing scale, cartographic projection and symbol, compilation helps to reveal many features of spatial distribution of objects and phenomena. For the purposes of this research, methods of statistical analysis are used, among others. The map resulting from cartographic compilation provides a detailed description of location relations on the mathematically (precisely) defined basis of a fragment of the surface of the Earth in accordance with a well-considered concept of the organization of the structure of objects and phenomena of actual reality. This concept usually includes general scientific opinion, which provides sound grounds for cartography to be considered as a nomothetic science which also integrates other disciplines. This also explains the opinion which is popular among geographers that only cartographic structures (maps) make possible the formulation of hypotheses and conclusions in a purely geographic manner. 